\title{
Application of Fourier transform infrared spectroscopy to biomolecular profiling of cultured fibroblast cells from Gaucher disease patients: A preliminary investigation
}

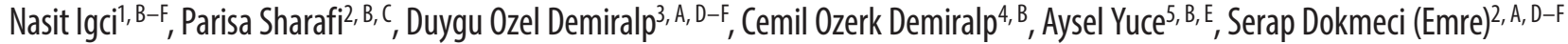 \\ ${ }^{1}$ Department of Molecular Biology and Genetics, Faculty of Sciences and Arts, Nevsehir Haci Bektas Veli University, Turkey \\ ${ }^{2}$ Medical Biology Department, Faculty of Medicine, Hacettepe University, Ankara, Turkey \\ ${ }^{3}$ Biomedical Engineering Department, Faculty of Engineering, Ankara University, Turkey \\ ${ }^{4}$ Plastic and Reconstructive Surgery Department, Ataturk Training and Research Hospital, Ankara, Turkey \\ ${ }^{5}$ Pediatric Gastroenterology, Hepatology and Nutrition Unit, Ihsan Dogramaci Children Hospital, Faculty of Medicine, Hacettepe University, Ankara, Turkey \\ A - research concept and design; B - collection and/or assembly of data; $C$ - data analysis and interpretation; \\ $D$ - writing the article; $E$ - critical revision of the article; $F$ - final approval of article
}

Address for correspondence

Duygu Ozel Demiralp

E-mail:ddemiralp@ankara.edu.tr

Funding sources

This study was partially funded by Hacettepe University Scientific Research Projects Coordination Unit, Ankara, Turkey (Projekt No. 901101008).

Conflict of interest

None declared

Acknowledgements

We would like to thank Ankara University Biotechnoogy Institute for providing laboratory facility for spectroscopic measurements.

Received on September 21, 2015

Revised on May 11, 2016

Accepted on 0ctober 12, 2016

DOI

10.17219/acem/65784

Copyright

Copyright by Author(s)

This is an article distributed under the terms of the

Creative Commons Attribution Non-Commercial License

(http://creativecommons.org/licenses/by-nc-nd/4.0/)

\begin{abstract}
Background. Gaucher disease (GD) is defined as an autosomal recessive disorder resulting from the deficiency of glucocerebrosidase (E.C. 3.2.1.45). Glucocerebrosidase is responsible for the degradation of glucosylceramide into ceramide and glucose. The deficiency of this enzyme results in the accumulation of undegraded glucosylceramide, almost exclusively in macrophages. With Fourier transform infrared (FTIR) spectroscopy, the complete molecular diversity of the samples can be studied comparatively and the amount of the particular materials can be determined. Also, the secondary structure ratios of proteins can be determined by analysing the amide peaks.
\end{abstract}

Objectives. The primary aim of this study is to introduce FTIR-ATR spectroscopy technique to GD research for the first time in the literature and to assess its potential as a new molecular method.

Material and methods. Primary fibroblast cell cultures obtained from biopsy samples were used, since this material is widely used for the diagnosis of GD. Intact cells were placed onto a FTIR-ATR crystal and dried by purging nitrogen gas. Spectra were recorded in the mid-infrared region between $4500-850 \mathrm{~cm}^{-1}$ wavenumbers. Each peak in the spectra was assigned to various organic biomolecules by comparing their wavenumbers with the reference values in the literature. A quantitative analysis was performed using peak areas and we also used a hierarchical cluster analysis as a multivariate spectral analysis.

Results. We obtained FTIR spectra of fibroblast samples and assigned the biomolecule origins of the peaks. We observed individual heterogeneity in FTIR spectra of GD fibroblast samples, confirming the well-known phenotypic heterogeneity in GD at the molecular level. Significant alterations in protein, lipid and carbohydrate levels related to the enzyme replacement therapy were also observed, which is also supported by cluster analysis.

Conclusions. Our results showed that the application of FTIR spectroscopy to GD research deserves more attention and detailed studies with an increased sample size in order to evaluate its potential in the diagnosis and follow-up of GD patients.

Key words: FTR, Gaucher disease, fibroblast 
Gaucher disease (GD) is the most frequent lysosomal glycolipid storage disorder, defined as an autosomal recessive disease resulting from the deficiency of glucocerebrosidase (GBA) (E.C.3.2.1.45), a lysosomal hydrolase, also known as acid- $\beta$-glucosidase. GBA is responsible for the degradation of glucosylceramide (GC), a natural glycosphingolipid, into ceramide and glucose. The deficiency of this enzyme results in the accumulation of undegraded glucosylceramide, almost exclusively in macrophages. GD is a multisystemic disorder, characterized by a spectrum of the clinical subtypes. GD is classically divided into non-neuronopathic type I (OMIM \#230800) and neuronopathic types II (OMIM \#230900) and III (OMIM \#231000) variants. Although the most symptomatic individuals have hematological, visceral and skeletal diseases, there is a wide variation in the pattern and severity of extra-neurological involvement among these patients. Enzyme replacement therapy (ERT) is the preferred strategy in the treatment of GD. ${ }^{1-3}$

Infrared (IR) radiation is a noninvasive and nondestructive type of radiation and it causes the vibration of the covalent bonds of molecules when absorbed by tissues, body fluids or cells. Fourier transform infrared (FTIR) spectroscopy is a widely-used and preferred method of IR spectroscopy due to its speed and sensitivity. The resulting peaks correspond to the frequencies of vibrations between the bonds of the atoms making up the sample., ${ }^{4,5}$ Different functional groups absorb characteristic frequencies and the resulting spectrum represents the unique molecular fingerprint of the sample material. ${ }^{6}$ Attenuated total reflectance (ATR) is one of the approaches for FTIR sampling, which allows us to measure the analyte directly by using the ATR crystal. With FTIR, the complete molecular diversity of the samples (all types of organic and many types of inorganic compounds) can be studied comparatively with the knowledge of the peak origins, such as lipids, proteins, carbohydrates and nucleic acids. The amount of the particular compounds can also be determined by this method. Additionally, the secondary structures of proteins that are important for understanding the molecular mechanisms underlying the diseases can be determined by comparing the second derivatives of amide peaks (mainly Amide I peak) in FTIR spectrum that originate from proteins. ${ }^{7-12}$

The gold standard for the diagnosis of GD is the measurement of $\beta$-GBA activity in leukocytes or cultured fibroblasts obtained from the patients by skin punch biopsy. ${ }^{3}$ The primary aim of this preliminary study is to introduce and evaluate the potential of ATR-FTIR spectroscopy technique for biomolecular profiling of cultured fibroblast cells derived from GD patients, as well as to investigate the individual phenotypic heterogeneity of the disease at the molecular level.

\section{Material and methods}

\section{Patients and sample collection}

Study group consisted of 8 unrelated Turkish GD patients representing 5 different genotypes who were selected from among the patients admitted to Hacettepe University, Department of Pediatric Gastroenterology (Ankara, Turkey). There were also 2 healthy adult controls. The diagnosis was suspected on account of the clinical features, which included the age of onset, organomegaly, skeletal features, presence of progressive central nervous system symptoms, as well as reduced cellular GBA activity. Fibroblast cells were obtained from the patients by $0.4 \mathrm{~cm}$ skin punch biopsy from the forearm under sterile conditions, following their written informed consent, with the approval of the institutional ethical review board. Clinical features of GD patients are presented in Table 1.

\section{Fibroblast cell culture and sample preparation for FTIR spectroscopy}

For FTIR studies, primary skin fibroblast cell culture samples were used. The biopsy samples were washed twice with phosphate buffered saline (PBS) containing $1 \%$ fetal calf serum (FCS, Biochrome AG, Berlin, Germany), 3\% penicillin/streptomycin (Biochrome AG) and $3 \%$ amphotericin B solution (Biochrome AG). The biopsies were placed in $60 \mathrm{~mm}$ tissue culture dishes and minced. The small pieces were adhered onto the dishes with the help of a lancet and supplemented with $20 \%$ fetal bovine serum (FBS, Biochrome AG), 1\% penicillin-streptomycin and $2 \mathrm{mM}$ L-glutamine (Biochrome AG) in high glucose (4.5 mg/ml) DMEM (Biochrome AG). The cells were maintained in high glucose DMEM supplemented with $10 \%$ FBS, $1 \%$ penicillin-streptomycin and $2 \mathrm{mM} \mathrm{L-}$ glutamine in a humidified atmosphere containing 5\% $\mathrm{CO}_{2}$ at $37^{\circ} \mathrm{C}$. A $75 \mathrm{~cm}^{2}$ culture flask of fibroblast (90-95\% confluency) was washed with $1 \mathrm{X}$ PBS for 3-4 times and the fibroblasts were detached by mechanical scraping and counted. For the standardization of the spectroscopic measurements, after the total number of the detached cells was set to $5 \times 10^{6}$, each tube was centrifuged at $1000 \times \mathrm{g}$ and the cell pellets were resuspended in $300 \mu \mathrm{l}$ of $1 \mathrm{X}$ PBS for FTIR spectroscopy studies.

\section{FTIR spectroscopy data collection and evaluation}

Infrared spectra were obtained by a Bruker Tensor 27 FTIR (Bruker Optik GmbH, Ettlingen, Germany) equipped with a liquid $\mathrm{N}_{2}$ cooled photovoltaic Mercury Cadmium Telluride detector and a universal ATR cell with a ZnSe crystal (Pike Technologies, Wisconsin, U.S.A). Continuously purging $\mathrm{N}_{2}$ gas was provided during all the measurements. Samples were measured after hav- 
Table 1. Clinical information about the patients included in this study

\begin{tabular}{|c|c|c|c|c|}
\hline Patient No. & Diagnosis & Mutation & Age of diagnosis & Period of ERT \\
\hline G1 & Type I (M) & N370S/- & 4 years & 6 years \\
\hline G2 & Type III (S) & D409H/D409H & 21 months & 17 months \\
\hline G3 & Type I (M) & N370S/- & 21 months & - \\
\hline G4 & Type I (+ FMF) (M) & N370S/- & 10 years & 8 months \\
\hline G5 & Type III (S) & L444P/L444P & 8 months & - \\
\hline G6 & Type III (S) & L444P/L444P & 9 months & - \\
\hline G7 & Type I (S) & N370/RecAHI & 2 years & - \\
\hline G8 & Type I (S) & L296V/L296V & 3 years & 3 years \\
\hline
\end{tabular}

M - moderate; S - severe; ERT - enzyme replacement therapy; FMF - Familial Mediterranean Fever.

ing been dried on the crystal, similar to the method applied in the literature. ${ }^{14,15}$ Briefly, fibroblast cell samples were mixed gently prior to the measurements to obtain homogeneity. $2.5 \mu \mathrm{L}$ of cell suspension in PBS were spotted onto the ZnSe ATR crystal. The sample was dried on the crystal by evaporation using a mild $\mathrm{N}_{2}$ gas stream for $3 \mathrm{~min}$. PBS without cells was also measured under the same conditions and used as a background spectrum for subtraction. The air was recorded and subtracted automatically by the software before all the measurements. The spectra recorded in the mid-infrared region, between $4500-850 \mathrm{~cm}^{-1}$ wavenumbers and interferograms were accumulated for 50 scans at $4 \mathrm{~cm}^{-1}$ resolution at $22^{\circ} \mathrm{C}$ in the single-bounce ATR mode. Each sample was measured 3 times, the spectra were compared if they were identical and the average spectra were used for further analyses. All the data collection, manipulation and analyses were performed by OPUS software (Bruker Optik GmbH, Ettlingen, Germany).

PBS spectrum was subtracted from the sample spectra by using the OPUS software. The difference spectra were baselined using the rubber-band method and the resulting baselined spectra were used for the exact integration calculations. Min-max normalization was applied with respect to the Amide A (between $3500-3100 \mathrm{~cm}^{-1}$ ) and Amide I peaks (between $1700-1600 \mathrm{~cm}^{-1}$ ) for the regions between $3500-2750$ and $1800-850 \mathrm{~cm}^{-1}$ wavenumbers, respectively for illustrative purposes. The second derivatives of the absorbance spectra, in which the absorption maxima appear as the minima, were calculated using Savitzky-Golay algorithm with 9 smoothing points. For comparing protein secondary structures, relative intensity values of the second derivative peaks in the Amide I region (1700-1600 $\mathrm{cm}^{-1}$ ) were used; they were obtained by automated peak picking after vector normalization.

In order to achieve spectral differentiation, according to the molecular fingerprints of the samples, a cluster analysis (hierarchical clustering) was carried out using the OPUS software. Ward's algorithm with Euclidian distances was used to construct the dendograms, which is known to give good predictions among the available algorithms. ${ }^{16,17}$ Sensitivity and specificity values were calculated for cluster dendrograms as described by Severcan et al. ${ }^{17}$

\section{Statistics}

The differences of the means were compared by Student's t-test. Levene's test for homogeneity of variances was performed prior to the statistical tests and Levene's p-values were taken into consideration while evaluating the results of Student's t-test. The p-values equal or less than 0.05 were considered as significantly different and the results were expressed as means \pm SD. SPSS 13.0 software was used for the analyses.

\section{Results}

\section{Biomolecular characterization of the fibroblast cells based on the FTIR spectrum}

We obtained FTIR spectra of the fibroblast cell samples between $4500-850 \mathrm{~cm}^{-1}$ wavenumbers in the mid-infrared region. The spectra were complex with many characteristic peaks. Fig. 1A shows the representative FTIR absorbance spectrum obtained by averaging all the spectra used in the analyses. According to our results, there are 2 main regions in the FTIR spectra of GD and control fibroblast cell samples: the region between $3500-2750 \mathrm{~cm}^{-1}$ (Fig. 1B), which can be considered as a lipid dominated region (except some contribution from proteins), and 1800$850 \mathrm{~cm}^{-1}$ (Fig. $1 \mathrm{C}$ ), which is referred to as a fingerprint region. ${ }^{18-20}$ We calculated the total lipid content as a sum of the areas of the peaks 2, 3, 4, 5, 6, 8, 9 and 13, which originate from lipids. The band between $4100-3580 \mathrm{~cm}^{-1}$ 
Fig. 1. Representative FTIR absorbance spectrum

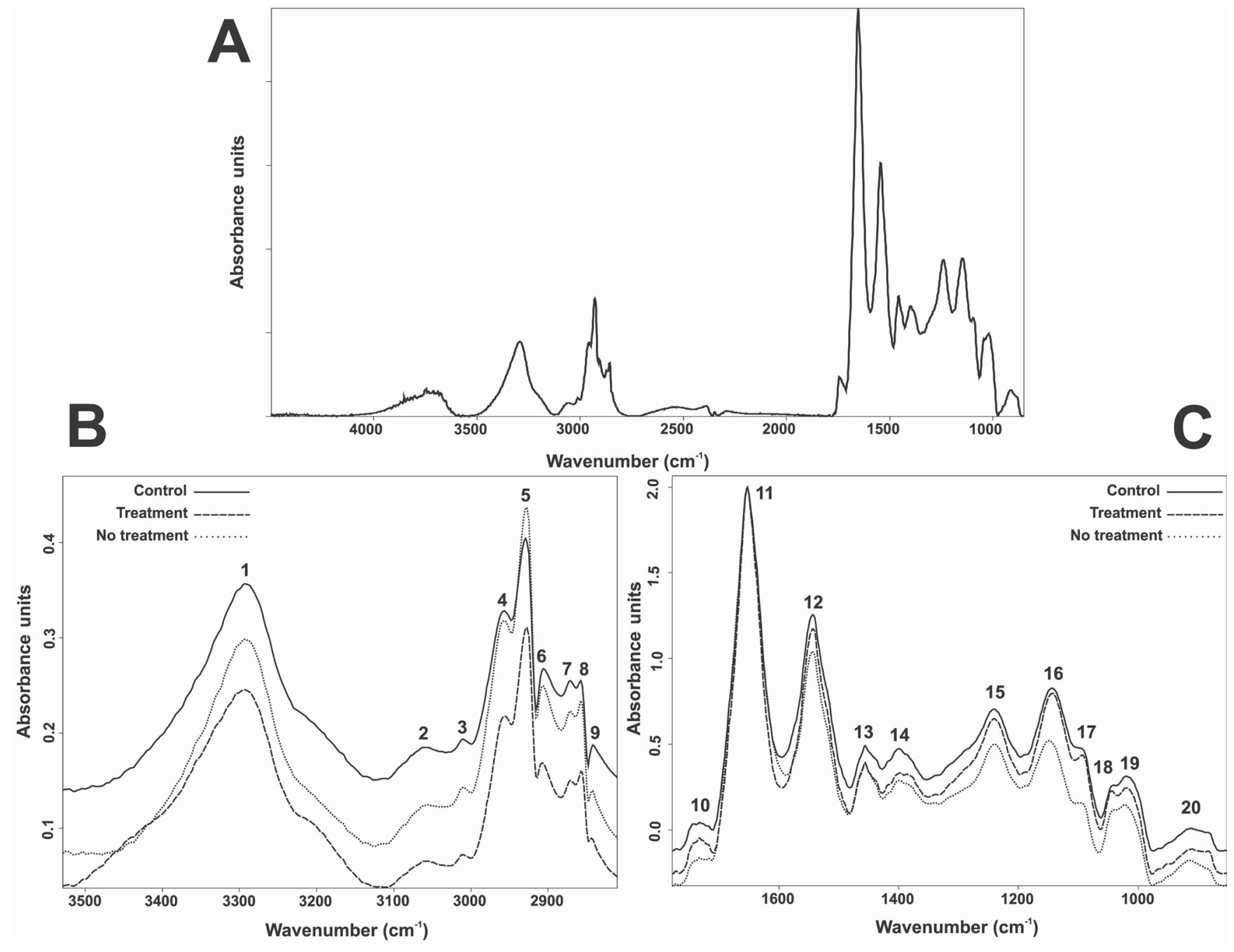

A - between $4500-850 \mathrm{~cm}^{-1}$ obtained by averaging all the spectra used in the analyses; B - between $3500-2750 \mathrm{~cm}^{-1} ; \mathrm{C}-1800-850 \mathrm{~cm}^{-1}$ wavenumbers. Refer to Table 2 for spectral assignments of numbered peaks. The stacked spectra show aletrations between mean spectra of control, treatment and notreatment samples, and were normalized with respect to the Amide I peak between $1700-1600 \mathrm{~cm}^{-1}$ after baseline correction.

was ignored, since it was originated from $\mathrm{O}-\mathrm{H}$ stretchings of residual $\mathrm{H}_{2} \mathrm{O}{ }^{21}$ Twenty major absorption peaks in our FTIR spectra, which are numbered in Fig. 1, were assigned in the present study to various biomolecules such as proteins, lipids, cholesterol esters, nucleic acids and carbohydrates (Table 2) by matching the wavenumbers with the references obtained from the literature (references are cited in the caption for Table 2).

Peaks at 3294 (Amide A), 3060 (Amide B), $2871\left(\mathrm{CH}_{3}\right.$ symmetric stretching), 1653 (Amide I) and $1544 \mathrm{~cm}^{-1}$ (Amide II) wavenumbers mainly originate from various bond vibrations of proteins (Table 2). Region between 3500-2750 $\mathrm{cm}^{-1}$ wavenumbers contains contribution mainly from lipids. $\mathrm{CH}_{3}$ asymmetric stretching $\left(2957 \mathrm{~cm}^{-1}\right)$, $\mathrm{CH}_{2}$ asymmetric $\left(2929 \mathrm{~cm}^{-1}\right)$ and symmetric $\left(2857 \mathrm{~cm}^{-1}\right)$ stretching, olefinic $=\mathrm{CH}\left(3011 \mathrm{~cm}^{-1}\right)$ and $\mathrm{C}-\mathrm{H}\left(2843 \mathrm{~cm}^{-1}\right)$ stretching modes are the major bond vibrations in this region, originating from lipids (Table 2). Also, there is a peak at $1455 \mathrm{~cm}^{-1}$ that was assigned to $\mathrm{CH}_{2}$ bending of lipids.
Saturated ester $\mathrm{C}=\mathrm{O}$ stretching at $1732 \mathrm{~cm}^{-1}$ originates from the cholesterol esters or phospholipids. Peaks between 1093-914 $\mathrm{cm}^{-1}$ wavenumbers mainly result from phosphate groups of nucleic acids, phospholipids and phosphorylated proteins and $\mathrm{C}-\mathrm{O}$ stretching of carbohydrates.

\section{Comparative analysis of the levels of biomolecules}

The intensity or area of a particular FTIR absorption peak reflects the amount of the assigned compound for that wavenumber. ${ }^{12,19}$ Although the primary purpose of this preliminary study is to introduce the method to GD research rather than to understand the molecular mechanisms underlying GD, we also included the control group in order to see if there were very prominent differences. First of all, the quantitative and qualitative comparisons were performed between GD and control groups in terms of spectral differences. We observed overlapping peaks 
Table 2. Peak assignments of major absorbance peaks of fibroblast samples detected in the present study and their definition with relative organic compounds based on the literature 6,12,17-19,22-26 (peak numbers illustrated in Fig. 1B, C)

\begin{tabular}{|c|c|c|c|}
\hline Peak No. & $\begin{array}{c}\text { Wavenumber } \\
\left(\mathrm{cm}^{-1}\right)\end{array}$ & Definition & Organic compound \\
\hline 1 & 3294 & $\begin{array}{l}\text { Amide } \mathrm{A} \text {; mainly } \mathrm{N}-\mathrm{H} \text { stretching of proteins with contribution from } \\
\text { intermolecular } \mathrm{H} \text { bondings and } \mathrm{O}-\mathrm{H} \text { stretching mode of polysaccharides }\end{array}$ & mainly proteins \\
\hline 2 & 3060 & Amide $\mathrm{B} ; \mathrm{C}-\mathrm{N}, \mathrm{N}-\mathrm{H}$ stretching of proteins & proteins \\
\hline 3 & 3011 & olefinic, $\mathrm{C}-\mathrm{H}$ stretching mode of the $\mathrm{HC}=\mathrm{CH}$ groups & unsaturated lipids \\
\hline 4 & 2957 & $\mathrm{CH}_{3}$ antisymmetric stretching & mainly lipids \\
\hline 5 & 2929 & $\mathrm{CH}_{2}$ antisymmetric stretching & mainly lipids \\
\hline 6 & 2907 & $\mathrm{CH}_{2}$ and $\mathrm{CH}_{3}$ stretching of phospholipids, cholesterol and creatine & mainly lipids \\
\hline 7 & 2871 & $\mathrm{CH}_{3}$ symmetric stretching & mainly proteins \\
\hline 8 & 2858 & $\mathrm{CH}_{2}$ symmetric stretching & mainly lipids \\
\hline 9 & 2843 & $\mathrm{C}-\mathrm{H}$ stretching & mainly lipids \\
\hline 10 & 1732 & Saturated ester $\mathrm{C}=\mathrm{O}$ stretching & $\begin{array}{l}\text { cholesterol esters, phospholipids, } \\
\text { ester functional groups in lipids }\end{array}$ \\
\hline 11 & 1653 & Amide $1 ; 80 \%$ C=O stretching, 10\% N-H bending, 10\% C-N stretching & proteins \\
\hline 12 & 1544 & Amide $I I ; 60 \% \mathrm{~N}-\mathrm{H}$ bending, $40 \% \mathrm{C}-\mathrm{N}$ stretching & proteins \\
\hline 13 & 1455 & $\mathrm{CH}_{2}$ bending & lipids \\
\hline 14 & 1396 & COO-symmetric stretching & fatty acids \\
\hline 15 & 1241 & $\mathrm{PO}_{2}^{-}$antisymmetric stretching (non $\mathrm{H}$-bonded) & $\begin{array}{l}\text { nucleic acids, phophorylated proteins } \\
\text { and phospholipids }\end{array}$ \\
\hline 16 & 1147 & C-O stretching & carbohydrates/glycogen, nucleic acids \\
\hline 17 & 1094 & $\begin{array}{l}\mathrm{PO}_{2}^{-} \text {ionized symmetric stretching (fully } \mathrm{H} \text {-bonded) of phosphodiester groups, } \\
\qquad \mathrm{C}-\mathrm{O} \text { stretcing }\end{array}$ & $\begin{array}{l}\text { nucleic acids, phospholipids, glycogen, } \\
\text { oligosaccharides and glycolipids }\end{array}$ \\
\hline 18 & 1041 & $\begin{array}{c}\mathrm{C}-\mathrm{O} \text { stretching, coupled with } \mathrm{C}-\mathrm{O} \text { bending of the } \mathrm{C}-\mathrm{OH} \text { groups } \\
\text { of carbohydrates }\end{array}$ & oligosaccharides, polysaccharides \\
\hline 19 & 1021 & $\begin{array}{l}\mathrm{C}-\mathrm{O} \text { stretching, coupled with } \mathrm{C}-\mathrm{O} \text { bending of the } \mathrm{C}-\mathrm{OH} \text { groups } \\
\text { of carbohydrates }\end{array}$ & oligosaccharides, polysaccharides \\
\hline 20 & $976-875$ & $\mathrm{C}-\mathrm{N}^{+}-\mathrm{C}$ stretching & $\begin{array}{c}\text { nucleic acids (DNA, RNA), ribose- } \\
\text { phosphate main chain vibrations of RNA, } \\
\text { phosphate monoesters }\end{array}$ \\
\hline
\end{tabular}

of GD and control samples and detected some quantitative differences and minor peak shifts between GD and control group, as shown in Fig. 1B, C. Means of absorbance peak area values of GD and control groups obtained by integration are presented as bar graphics in Fig. 2A. According to our results, lipid, protein and carbohydrate levels were increased in GD when compared to controls.

Moreover, we grouped GD samples according to the severity (severe or moderate), type (Type I, II and III) and treatment (ERT) condition (Table 1). We observed statistically significant differences between the samples of patients who had been taking ERT treatment and those who had not received treatment. The areas of the peaks at 3294,
1653, 1455, 1396 and $1021 \mathrm{~cm}^{-1}$ wavenumbers indicating lipids, proteins and polysaccharides increased in the samples after treatment (Fig. 1B, 1C, 2B). However, we did not observe a significant decrease in the areas of the peaks originating from $\mathrm{CH}_{2}$ and $\mathrm{CH}_{3}$ anti-symmetric and symmetric stretching, which are the main IR absorption peaks of lipid backbone, including acyl chains of GC.

Since one of the aims of the present study is to investigate the phenotypic heterogeneity of GD fibroblast cells by FTIR, we also analyzed the individual variation regarding the peak patterns of the samples. We observed some differences between the spectra in terms of peak area and shifts (Fig. 3). 
Fig. 2. Demonstration of mean values ( \pm SEM) of baselined absorbance band areas

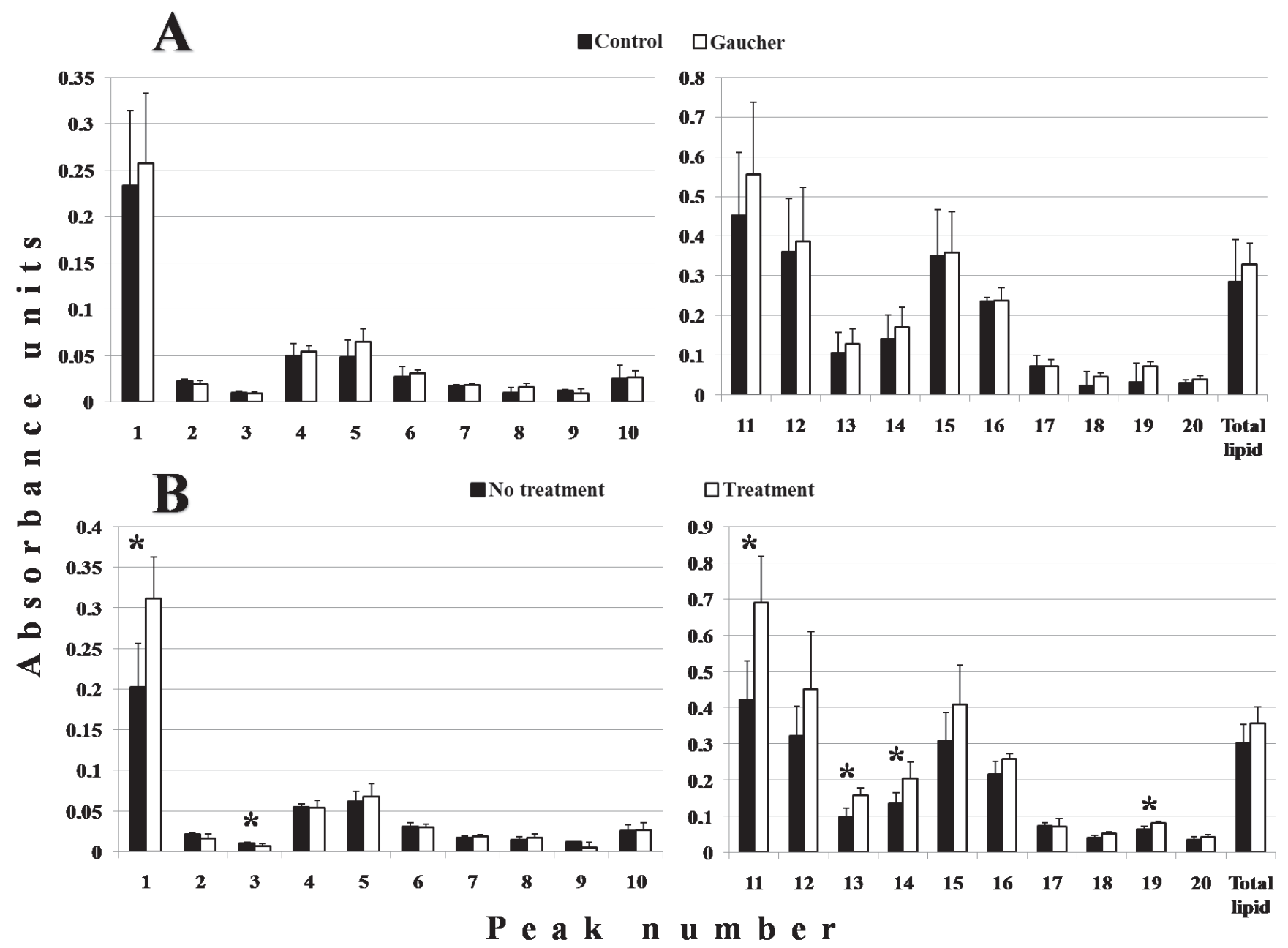

A - GD and control; B - treatment and no-treatment groups based on our results. Peak numbers are illustrated in Fig. 1B, C and spectral assignments are given in Table 2.

Fig. 3. Individual variation in the absorbance spectra of GD patients (G1-G8) and controls (C1, C2)

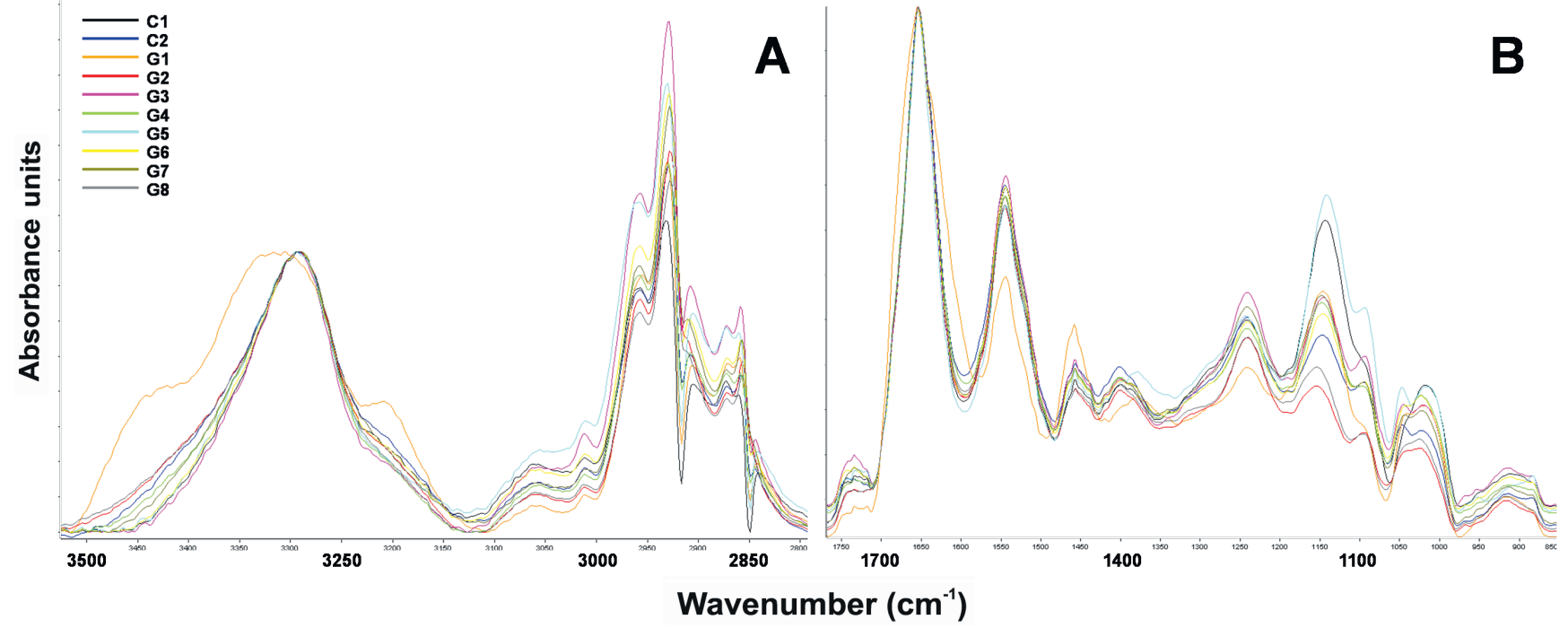

A - between 3500-2750 cm-1; B - between 1800-850 $\mathrm{cm}^{-1}$ wavenumbers. The spectral range between $3500-2750 \mathrm{~cm}^{-1}$ and $1800-850 \mathrm{~cm}^{-1}$ were normalized with respect to the Amide A band between $3500-3100 \mathrm{~cm}^{-1}$ and Amid I band between 1700-1600 $\mathrm{cm}^{-1}$, respectively after baseline correction. 


\section{Comparative analysis of the protein secondary structures}

FTIR peaks, including Amide I, consist of several sub-peaks, which can be obtained by derivatization. ${ }^{19}$ We analyzed the second derivative spectra of Amide I peaks $\left(1653 \mathrm{~cm}^{-1}\right)$ in order to determine and compare protein secondary structures, which is very important in biological systems. ${ }^{9,23}$ Amide I peak is sensitive to protein conformational changes and is usually used to determine protein secondary structures based on FTIR spectra. ${ }^{7-11}$ According to our results, the second derivative of the Amide I peak had 5 sub-peaks at 1697, 1684, 1654, 1636 and $1615 \mathrm{~cm}^{-1}$ (Fig. 4). Peak assignments for protein secondary structures are given in Table 3 . We observed slight differences and peak shifts between the control and GD groups (Table 4). $\alpha$-helix structure was observed as being slightly increased in GD, while $\beta$-sheet structure was decreased. These structures decreased slightly in samples after treatment, compared to no-treatment group. Statistical tests did not reveal significant differences between GDcontrol, type I-II-III, severe-moderate and with-without treatment groups in terms of peak intensities and shifts.

Also, we investigated the individual variations in the second derivative peak patterns of the Amide I peak (Fig. 4). We observed individual alterations on protein secondary structures in terms of peak intensity and frequency shifts.

Table 3. Peak assignments for secondary derivative spectrum of Amide I peak indicating protein secondary structures based on the literature. ${ }^{6-8,10,1}$ See Fig. 4 for peak numbers

\begin{tabular}{|c|c|c|}
\hline $\begin{array}{c}\text { Peak } \\
\text { No. }\end{array}$ & $\begin{array}{r}\text { Wavenumber } \\
\left(\mathrm{cm}^{-1}\right)\end{array}$ & $\begin{array}{r}\text { Protein secondary structure } \\
\text { I }\end{array}$ \\
\hline II & 1697 & aggregated strand \\
\hline III & 1684 & antiparallel $\beta$-sheet, $\beta$-turns \\
\hline IV & 1654 & a-helix \\
\hline V & 1615 & B-sheet \\
\hline
\end{tabular}

Fig. 4. Second derivative spectra of Amide I absorption peak of the samples between 1700-1600 $\mathrm{cm}^{-1}$ wavenumbers (with a center at $1653 \mathrm{~cm}^{-1}$ ), which demonstrates main protein secondary structures and individual variation. Absorption maxima appear as minima and the spectra were vector normalized. Refer to Table 3 for peak numbers and their assignments

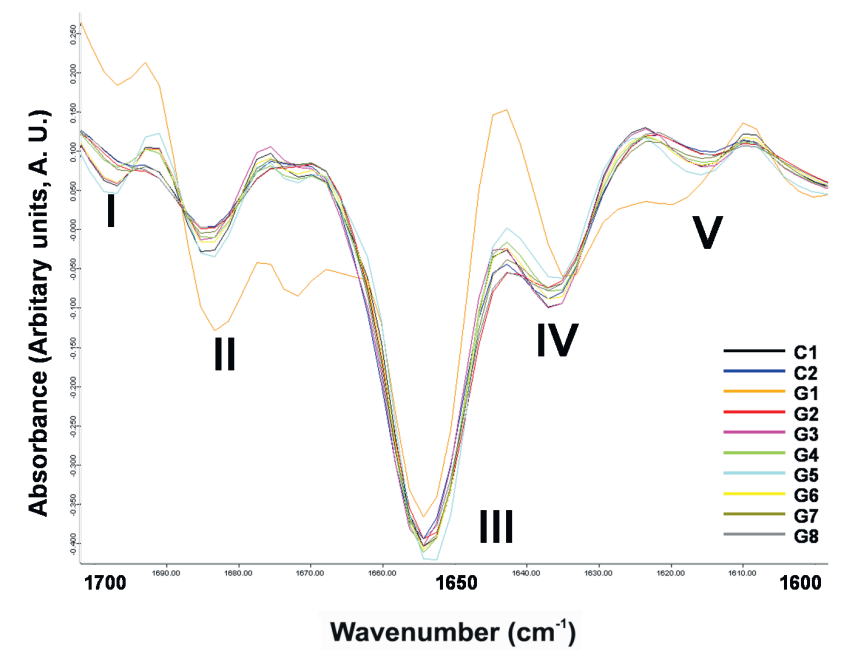

\section{Classification by hierarchical cluster analysis}

We performed hierarchical cluster analysis in order to achieve spectral differentiation according to the molecular fingerprints of the samples. The resulting dendrograms were evaluated in regard to such clinical features as severity, type of the disease, mutation and treatment condition. Our analyses yielded a classification between the sample of patients who had been taking ERT treatment and those who were not at the time of sampling, based on the 2 main spectrum areas (lipid and fingerprint regions) of the min-max normalized spectra (Fig. 5A).

In the present study, we also observed partial differentiation within GD group according to the severity of the disease, but it was not as significant as the obtained classification related to the treatment. Using the region between $3035-2820 \mathrm{~cm}^{-1}$ after the second derivative and vector normalization preprocessings, we obtained a dendrogram which partially classified GD patients into severe and moderate groups (Fig. 5B).

Table 4. Means of vector normalized second derivative relative peak intensities in Amide I region of GD and control groups. Relative intensity values obtained after peak picking by OPUS software. See Fig. 4 for peak numbers and Table 3 for their spectral assignments

\begin{tabular}{|c|c|c|c|c|}
\hline Peak No. & Gaucher disease & Control & GD before treatment & GD after treatment \\
\hline । & $0.014 \pm 0.015$ & $0.015 \pm 0.021$ & $0.024 \pm 0.016$ & $0.004 \pm 0.005$ \\
\hline$\|$ & $0.095 \pm 0.026$ & $0.089 \pm 0.008$ & $0.087 \pm 0.007$ & $0.104 \pm 0.037$ \\
\hline III & $0.435 \pm 0.033$ & $0.428 \pm 0.001$ & $0.450 \pm 0.017$ & $0.420 \pm 0.040$ \\
\hline IV & $0.076 \pm 0.018$ & $0.085 \pm 0.012$ & $0.078 \pm 0.016$ & $0.074 \pm 0.022$ \\
\hline V & $0.013 \pm 0.007$ & $0.012 \pm 0.012$ & $0.015 \pm 0.007$ & $0.011 \pm 0.007$ \\
\hline
\end{tabular}


Fig. 5. Representation of a cluster analysis dendrogram
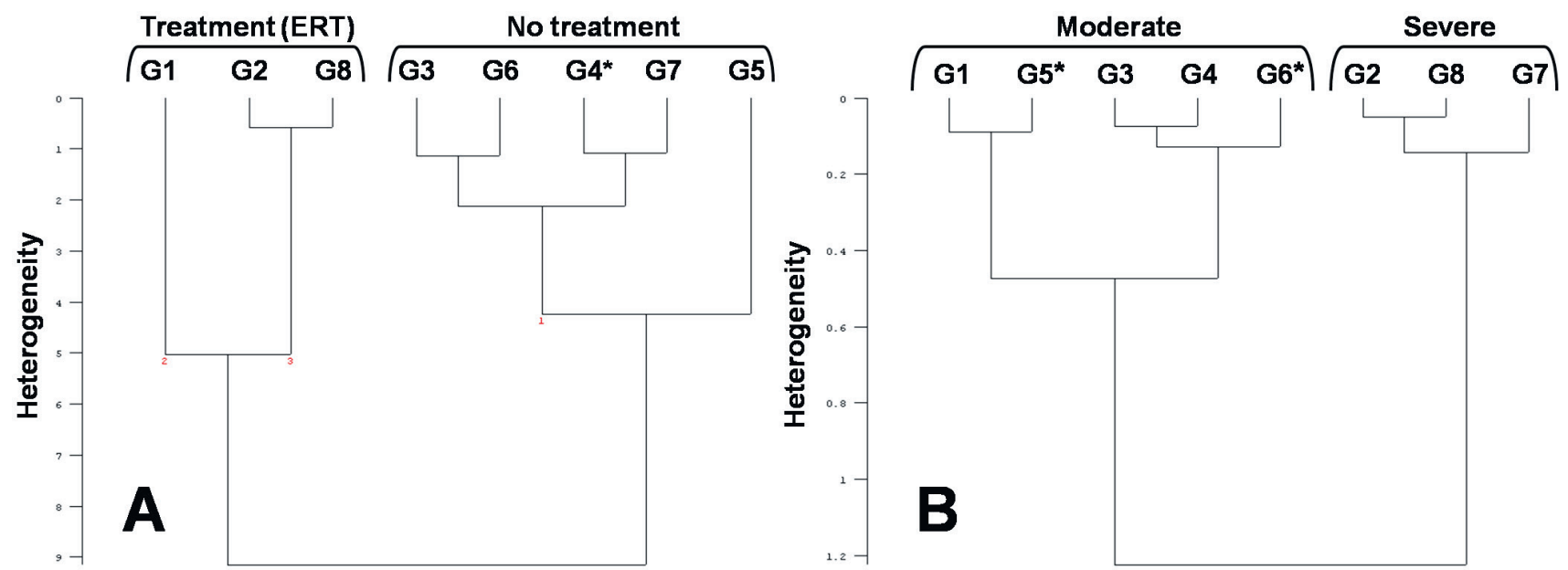

A - the samples of patients with or without treatment; B - the samples of patients diagnosed as severe or moderate; * misgrouped samples; sensitivity and specificity are $75 \%$ and $100 \%$ for treatment group, 100\% and 75\% for no-treatment group classification whereas these values are $60 \%$ and $100 \%$ for severe and $100 \%$ and $60 \%$ for moderate group classifications, respectively.

\section{Discussion}

Our optimized procedure allowed us to characterize the major biomolecules in the cultured fibroblast cells of GD patients in a qualitative and quantitative manner. According to our results, lipid, protein and carbohydrate levels were found to be increased in GD compared to controls. GC (a glycosphingolipid) is the major GD-related lipid type that accumulates in the cells with GD. Secondly, glucosysphingosine is also accumulated by GD cells but at much lower concentrations. ${ }^{27}$ A combined increase in the lipid and carbohydrate levels may reflect increased GC storage in lysosomes, as a result of the deficiency of GBA in GD patients. Since GD is a rare disease, our sample size is enough for a preliminary study aiming to introduce the method. We observed some significant molecular alterations (e.g., lipid, protein and carbohydrate levels) between groups with and without treatment. A comparative follow-up study with a larger sample size of GD and controls should be done in order to show correlations between the biomolecule levels (especially GC) and GD condition.

Moreover, our analyses on the spectral patterns revealed that GD fibroblast samples showed an individual variation at the molecular level. These alterations were mainly in protein, carbohydrate and fatty acid levels and structures, according to our results. More than 250 GDrelated mutations in the GBA gene have been identified to date. ${ }^{2}$ Emre et al. reported that L444P and N370S were the most prevalent mutations among Turkish GD patients. ${ }^{13}$ According to the literature, genotype-phenotype correlation is not seen in GD and clinical symptoms show heterogeneity. ${ }^{1,2,13}$ The results of the present study also showed no correlation between the genotype and the molecular fingerprint of GD fibroblast samples, confirming the diverse phenotypic expression and heterogeneity in GD. Additionally, our results showed that phenotypic variation must be taken into consideration in FTIR spectroscopic studies on GD and the sample size must be accordingly large to eliminate individual variations.

Our results have also indicated conformational changes in proteins between experiment groups. However, our small sample size did not allow us to perform comprehensive statistical tests for detecting possible significant correlations. Since the main purpose of this preliminary study was to introduce FTIR spectroscopy to GD research, rather than to reveal the molecular mechanisms of the disease, our results would still be useful for the method optimization as a reference work. Our results also showed that GD fibroblast samples expressed phenotypic heterogeneity in terms of the second derivative peak pattern reflecting the change in protein conformation.

Our preliminary multivariate cluster analysis yielded a spectral classification of the groups with and without treatment, suggesting that the treatment process of GD may cause alterations in the level of biomolecules in GD fibroblasts. In our study, only 1 sample with treatment (G4) was classified in no-treatment group. This misgrouping may be related to the duration of the treatment, since G4 patients had the shortest treatment period, compared to other patients. Our hierarchical cluster analysis results supported our statistical tests made by using individual peak areas. The classification regarding the severity of the disease was less significant. G5 and G6 patients were clinically diagnosed as severe but classified into the moderate group in the dendrogram (Fig. 5B), posssibly as a result of the phenotypic heterogeneity of the samples.

As a summary, primary skin fibroblast cell culture samples obtained from GD patients were studied by using FTIR-ATR for the first time to introduce the technique 
and to assess the potential of molecular IR fingerprints as an alternative approach in research related to lysosomal glycolipid storage disorders. We assigned different peaks of the complex FTIR spectrum to various bioorganic molecules. We observed significant differences between the groups with or without treatment, indicating structural and functional alterations due to the ERT. Also, we observed individual variations reflecting the phenotypic heterogeneity of GD at the molecular level.

Our results showed that FTIR spectroscopy was a rapid and sensitive technique and had the ability to give detailed information about important functional groups of bioorganic molecules in fibroblast samples that are widely used for the diagnosis of GD. Our study also showed that this research tool might provide molecular insights into the pathophysiology of GD. FTIR spectroscopy has already been used in medical diagnostics for some diseases as an alternative to well-known biochemical and histochemical methods and it is suitable for routine use. ${ }^{28,29}$ The present study was a complementary investigation to our ongoing proteomic analyses of GD and allowed us to carry our reserarch from the proteomic level to metabolomics in the biology systems frame. We attempted to introduce and apply FTIR spectroscopy to make molecular characterization of GD and our results showed that the application of this technique in GD research deserves further investigation to assess its potential in the diagnosis and monitoring of GD. Therefore, detailed studies should be done with an increased sample size.

\section{References}

1. CoxTM. Gaucher disease: Understanding the molecular pathogenesis of sphingolipidoses. J Inherit Metab Dis. 2001;24:106-121.

2. Hruska KS, LaMarca ME, Scott CR, Sidransky E. Gaucher disease: Mutation and polymorphism spectrum in the glucocerebrosidase gene (GBA). Hum Mutat. 2008;2:567-583.

3. Charrow J, Esplin JA, Gribble TJ, et al. Gaucher disease: Recommendations on diagnosis, evaluation and monitoring. Arch Intern Med. 1998;158:1754-1760.

4. Boydston-White S, Gopen T, Houser S, Bargonetti J, Diem M. Infrared spectroscopy of human tissue. V. Infrared spectroscopic studies of myeloid leukemia (ML-1) cells at different phases of the cell cycle. Biospectroscopy. 1999;5:219-227.

5. Sherman Hsu C-P. Infrared spectroscopy. In: Settle FA, ed. Handbook of instrumental techniques for analytical chemistry. New Jersey, NJ: Prentice Hall; 1997:247-283.

6. Baker MJ, Gazi E, Brown MD, Shanks JH, Gardner P, Clarke NW. FTIR-based spectroscopic analysis in the identification of clinically aggressive prostate cancer. Brit J Cancer. 2008;99:1859-1866.

7. Adiguzel Y, Haris PI, Severcan F. Screening of proteins in cells and tissues by vibrational spectroscopy. In: Severcan F, Haris PI. Vibrational Spectroscopy in Diagnosis and Screening. $1^{\text {st }}$ ed. Amsterdam: IOS Press BV; 2012:53-108.

8. Arrondo JLR, Muga A, Castresana J, Bernabeu C, Goñi FM. An infrared spectroscopic study of $\beta$-galactosidase structure in aqueous solutions. FEBS Lett. 1989;252:118-120.

9. Constantino HR, Chen B, Griebenow K, Hsu CC, Shire SJ. Fouriertransform infrared spectroscopic investigation of the secondary structure of aqueous and dried recombinant human deoxyribonuclease I. Pharm Pharmacol Commun. 1998:4:391-395.

10. Haris PI, Severcan F. FTIR spectroscopic characterization of protein structure in aqueous and non-aqueous media. J Mol Catal B-Enzym. 1999;7:207-221.
11. Nabedryk E, Garavito RM, Breton J. The orientation of $\beta$-sheets in porin: A polarized Fourier transform infrared spectroscopic investigation. Biophys J. 1988;53:671-676.

12. Toyran N, Lasch P, Naumann D, Turan B, Severcan F. Early alterations in myocardia and vessels of the diabetic rat heart: An FTIR microspectroscopic study. Biochem J. 2006;397:427-436.

13. Emre S, Gürakan F, Yüce A, Rolf A, Scott R, Özen H. Molecular analysis of Turkish Gaucher disease patients: Identification of novel mutations in glucocerebrosidase (GBA) gene. Eur J Med Genet. 2008;51:315-321.

14. Aksoy C, Guliyev A, Kilic E, Uckan D, Severcan F. Bone marrow mesenchymal stem cells in patients with beta thalassemia major: Molecular analysis with attenuated total reflection - Fourier transform infrared spectroscopy study as a novel method. Stem Cells Dev. 2012;21:2000-2011.

15. Gasper R, Mijatovic T, Bénard A, Derenne A, Kiss R, Goormaghtigh E. FTIR spectral signature of the effect of cardiotonic steroids with antitumoral properties on a prostate cancer cell line. Biochim Biophys Acta. 2010;1802:1087-1094.

16. Lasch P, Haensch W, Naumann D, Diem M. Imaging of colorectal adenocarcinoma using FT-IR microspectroscopy and cluster analysis. Biochim Biophys Acta. 2004;1688:176-186.

17. Severcan F, Bozkurt O, Gurbanov R, Gorgulu G. FT-IR spectroscopy in diagnosis of diabetes in rat animal model. $J$ Biophoton. 2010;3:621-631.

18. Schmitt J, Flemming H-C. FTIR-spectroscopy in microbial and material analysis. Int Biodeter Biodegr. 1998;41:1-11.

19. Severcan F, Toyran N, Kaptan N, Turan B. Fourier transform infrared study of the effect of diabetes on rat liver and heart tissues in the $\mathrm{C}-\mathrm{H}$ region. Talanta. 2000;53:55-59.

20. Walsh MJ, Fellous TG, Hammiche A, et al. Fourier transform infrared microspectroscopy identifies symmetric $\mathrm{PO}_{2}^{-}$modifications as a marker of the putative stem cell region of human intestinal crypts. Stem Cells. 2008;26:108-118.

21. Che Man YB, Mirghani MES. Rapid method for determining moisture content in crude palm oil by Fourier transform infrared spectroscopy. JAOCS. 2000;77:631-637.

22. Severcan F, Akkas SB, Turker S, Yucel R. Methodological approaches from experimental to computational analysis in vibrational spectroscopy and microspectroscopy. In: Severcan F, Haris PI. Vibrational Spectroscopy in Diagnosis and Screening. $1^{\text {st }}$ ed. Amsterdam: IOS Press BV; 2012:12-52.

23. Akkas SB, Severcan M, Yilmaz O, Severcan F. Effects of lipoic acid supplementation on rat brain tissue: An FTIR spectroscopic and neural network study. Food Chem. 2007;105:1281-1288.

24. Colley CS, Kazarian SG, Weinberg PD, Lever MJ. Spectroscopic imaging of arteries and atherosclerotic plaques. Biopolymers. 2004;74:328-335.

25. Gazi E, Dwyer J, Lockyer N, et al. The combined application of FTIR microspectroscopy and ToF-SIMS imaging in the study of prostate cancer. Faraday Discuss. 2004;126:41-59.

26. Movasaghi Z, Rehman S, Rehman I. Fourier transform infrared (FTIR) spectroscopy of biological tissues. Appl Spectrosc Rev. 2008;43: 134-179.

27. Grabowski GA, Leslie N, Wenstrup N. Enzyme therapy for Gaucher disease: The first 5 years. Blood Rev. 1998;12:115-133.

28. Hahn H, Pallua JD, Pezzei C, Huck-Pezzei V, Bonn GK, Huck CW. Infrared spectroscopy: A non-invasive tool for medical diagnostics and drug analysis. Curr Med Chem. 2010;17:2956-2966.

29. Bellisola G, Sorio C. Infrared spectroscopy and microscopy in cancer research and diagnosis. Am J Cancer Res. 2012;2:1-21. 